\title{
Sistem Pakar Mendiagnosa Penyakit Saraf Pusat Manusia Dengan Metode Certainty Factor
}

\author{
${ }^{1}$ Nelasari Situmeang, ${ }^{2}$ Sulindawaty \\ STMIK Pelita Nusantara Teknik Informatika \\ Medan, Indonesia \\ nelasari.s20@gmail.com, sulindawaty@gmail.com
}

\begin{abstract}
Abstrak
Penyakit saraf pusat adalah sekelompok gangguan neurologis yang memengaruhi struktur atau fungsi otak atau sumsum tulang belakang, yang secara kolektif membentuk sistem saraf pusat. Masyarakat pada umumnya masih banyak merupakan orang awam yang kurang memahami kesehatan saraf, sehingga banyak dari mereka mengabaikan gejala yang dialami dan mungkin merupakan gejala penyakit saraf pusat. Hal ini mungkin dikarenakan mahalnya biaya konsultasi, dan belum lagi dokter yang sulit ditemui karena faktur waktu. Didalam berbagai bidang pemanfaatan teknologi telah berkembang pesat, salah satunya adalah dalam bidang kesehatan, teknologi yang dimaanfaatkan salah satunya adalah sistem pakar. Sistem pakar adalah program komputer yang mempresentasikan dan melakukan penalaran dengan pengetahuan beberapa pakar untuk memecahkan masalah-masalah atau memberikan solusi. Perkembangan teknologi seperti sistem pakar ini tentunya juga didukung oleh metode dalam melakukan diagnosa, seperti Metode Certainty Factor. Untuk membuatkan sistem pakar yang dapat membantu masyarakat dalam konsultasi tentan penyakit saraf pusat yang dialami maka dirancang Sistem Pakar Mendiagnosa Penyakit Saraf Pusat Manusia Dengan Metode Certainty Factor.
\end{abstract}

\section{Kata Kunci : Saraf Pusat, Certainty Factor, Sistem Pakar, Teknologi}

\section{PENDAHULUAN}

Kesehatan saraf pusat adalah sesuatu yang sangat bernilai bagi manusia, karena siapapun tanpa pandang bulu dapat mengalami gangguan kesehatan saraf pusat. Manusia tentunya memiliki kerentanan terhadap serangan virus dan kuman penyakit saraf pusat, belum lagi terkadang kurangnya kepekaan terhadap gejala-gejala penyakit saraf pusatPada masyarakat umumnya masih banyak ditemukan orang-orang yang tidak terlalu memperhatikan dan tidak memahami masalah kesehatan saraf pusat. Di zaman dewasa ini kemudahan dengan adanya para dokter ahli maupun tenaga medis lainnya, sering sekali juga kita menemukan kelemahankelemahan dalam penanganan konsultasi, diantaranya jam dan waktu kerja (praktek) yang terbatas sehingga banyak pasien harus menunggu dalam antrian, belum lagi biaya konsultasi yang sangat mahal walau sekedar berkonsultasi. Oleh karena kelemahan-kelemahan tersebut, maka masyarakat selaku pengguna jasa sangat membutuhkan sebuah sistem yang dapat memberi kemudahan dalam mengdiagnosa penyakit yang dialami sehingga sedini mungkin agar dilakukan pencegahan dan pengobatan yang dapat dilakukan lebih awal maupun memudahkan masyarakat dalam berkonsultasi lebih lanjut dengan dokter ahli. Untuk meminimalisir kelemahan tersebut

maka dibutuhkan sebuah sistem yang dapat mendiagnosa suatu penyakit saraf pusat yaitu berupa suatu sistem pakar

Didalam berbagai bidang pemanfaatan teknologi sudah menjadi hal yang lumrah seperti yang kita ketahui, salah satunya adalah dalam bidang kesehatan atau medis, teknologi yang dimaanfaatkan salah satunya adalah sistem pakar. Sistem 
pakar adalah program komputer yang mempresentasikan dan melakukan penalaran dengan pengetahuan beberapa pakar untuk memecahkan masalah-masalah atau memberikan solusi. Perkembangan teknologi seperti sistem pakar ini tentunya juga didukung oleh metode-metode dalam melakukan diagnosa, seperti Metode Certainty Factor, Metode Teorema Bayes, dan metode lainnya.

Penelitian terkait dibidang kesehatan dengan Aplikasi Sistem Pakar Berbasis Web Untuk Mendiagnosa Penyakit Syaraf Pusat Dengan Metode Forward Chaining[1]. Hasil penelitian lainnya berupa program aplikasi sistem pakar yang mampu mendiagnosis penyakit sistem saraf pusat sebanyak 10jenis penyakit[2].

Dari latar belakang diatas dan juga penelitian sbelumnya, muncul sebuah maksud untuk melakukan penelitian dan merancang suatu program aplikasi sistem pakar yang nantinya di harapkan mampu membantu masyarakat awam dalam mendiagnosis penyakit saraf pusat pada manusia. Sistem pakarini diharapkan nantinya dapat membantu sehingga masyarakat awam tidak perlu lagi mengeluarkan biaya yang besar jika hanya untuk sekedar konsultasi tentang kesehatan saraf pusat.

\section{A. Identifikasi Masalah}

Berdasarkan latar belakang yang telah diuraikan sebelumnya, maka penilit membuat beberapa identifikasi masalah dalam perancangan sistem pakar yang akan dibangun yaitu :

1) Saat mengalami gejala penyakit yang berkaitandengan saraf pusat biasanya masyarakat awam hanya menebakbegitu saja tentang penyakit yang dialami.

2) Masyarakat pada umumnya tidak pergi konsultasi ke dokter dikarenakan biaya konsultasi yang mahal.

3) Disaat yang bersamaan dokter spesialis saraf pusat pada manusia juga pada umumnya sulit untuk dijumpai karena beberapa hal seperti sibuk, mahalnya biaya konsultasi, dan masih jarangnya dokter spesialis saraf.

\section{B. Tujuan Penelitian}

Tujuan dalam penelitian ini adalah untuk merancang dan membuat sistem pakar mendiagnosa penyakit saraf pusat pada manusia berdasarkan gejala-gejala yang dialami dengan metode certainty factor agar dapat membantu masyarakat yangawam tentang jenis penyakit saraf pusat pada manusia saat mengalami gejala-gejala yang berkaitan dengan penyakit sarafpusat pada manusia sehingga dapat mengurangi biaya konsultasi ke dokter spesialis saraf

\section{Manfaat Penelitian}

Manfaat yang diperoleh dari penelitian ini adalah :

1) Memberikan alat bantu diagnosa yang mudah digunakan.

2) User yang mengalami gejala penyakit saraf pusat dapat mengetahui jenis penyakit saraf pusat apa yang dialami berdasarkan gejala yang dialami.

3) Memudahkan pengguna untuk konsultasi lebih lanjut kepada dokter spesialis saraf.

\section{LANDASAN TEORI}

\section{Konsep Sistem}

Sistem adalah sekumpulan elemen yang saling terkait atau terpadu yang dimaksudkan untuk mencapai suatu tujuan. Sedangkan unsur- unsur ymg mewakili suatu sistern secara umum adalah masukan (input), pengolahan (processing) dankeluaran (output)[3].

\section{B. Kecerdasan Buatan (Artificial Intelligence)}

Kecerdasan Buatan (Artificial Intelligence) merupakan satu bagian ilmu komputer yang membuat agar mesin (komputer) dapat melakukan pekerjaan seperti dan sebaik yang dilakukan manusia[4].

\section{Sistem Pakar}

Sistem pakar adalah suatu sistem yang dirancang untuk dapat menirukan keahlian seorang pakar dalam 
menjawab pertanyaan dan memecahkan suatu masalah. Sitem pakar akan memberikan pemecahan suatu masalah yang didapat dari dialog dengan pengguna.[5]

1) Sejarah Sistem Pakar. Salah satu sistem pakar pertama adalah Healistic DENDRAL. Proyek DENDRAL dimulai pada tahun 1965 di Universitas Stanford. Sistem ini dikembangkan oleh J. Lederberg, seorang pakar kimia organik dan pemenang Nobel di bidang Ilmu Kimia. Sistem DENDRAL Heuristik menawarkan solusi bantuan di bidang kimia organik untuk menentukan formula struktur senyawa kimia yang telah diisolasi dari sampel tertentu. Dalam menentukan formula struktur dan informasi mengenai rumus kimia, seperti $\mathrm{C} 4 \mathrm{H} 9 \mathrm{OH}$ untuk butanol digunakan informasi yang telah diperoleh dengan mengenakan senyawa tersebut pada uji fisika, kimia dan spektrometri.[6]

2) Pengertian Sistem Pakar. Profesor Edward Feigenbaum dan Stanford University yang merupakan pionir dalam teknologi sistem pakar mendefinisikan sistem pakar sebagai sebuah program komputer pintar (Intelligent Computer Program) yang memanfaatkan pengetahuan (knowledge) dan prosedur inferensi (inference procedure) untuk memecahkan masalah yang cukup sulit hingga membutuhkan keahlian khusus dan manusia [7]

$D$.

Metode Certainty Factor

Certainty factor adalah suatu metode untuk membuktikan apakah suatu fakta itu pasti ataukah tidak pasti yang berbentuk metric yang biasanya digunakan dalam sistem pakar. Metode ini sangat cocok untuk sistem pakar yang mendiagnosis sesuatu yang belum pasti[8]

Nilai certainty factor ada 2, yaitu:

- Nilai certainty factor kaidah yang nilainya melekat pada suatu kaidah/rule tertentu dan besarnya nilai diberikan oleh pakar[9].

- Nilai certainty factor yang diberikan oleh pengguna untuk mewakili derajat kepastian/keyakinan atas premis (misalnya gejala, kondisi, ciri) yang dialami pengguna[9].

Ada dua cara dalam mendapatkan tingkat keyakinan (CF) dari sebuah rule[5], yaitu:

1) Metode Net Belief' yang diusulkan oleh E.H. Shortliffe dan B.G. Buchanan

$C F($ Rule $)=M B(H, E)-M D\left(H_{,} E\right)$

$\operatorname{MB}\left(\mathrm{H}_{s} \mathrm{E}\right)=\frac{\max [P(H \mid E), P(H)]-P(H)}{\operatorname{Max}[1,0]-P(H)} \quad P(H)=1$

$\operatorname{MB}(\mathrm{H}, \mathrm{E})=\frac{\min [P(H \mid E), P(H)]-P(H)}{\operatorname{Max}[1,0]-P(H)} \ldots \quad P(H)=0$

Dimana:

- $\quad \mathrm{CF}($ Rule $)=$ Faktor kepastian

- $\quad \mathrm{MB}(\mathrm{H}, \mathrm{E})=$ Measure of belief (ukuran kepercayaan) terhadap hipotesis $\mathrm{H}$, jika diberikan evidence $\mathrm{E}$ (antara 0 dan 1).

- $\quad \mathrm{MD}(\mathrm{H}, \mathrm{E})=$ Measure of disbelief (ukuran ketidakpercayaan) terhadap evidence $\mathrm{H}$, jika diberikan evidence E (antara 0 dan 1).

- $\mathrm{P}(\mathrm{H})=$ Probabilitas kebenara hipotesis $\mathrm{H}$.

- $\quad \mathrm{P}(\mathrm{H} \mid \mathrm{E})=$ Probalitas bahwa $\mathrm{H}$ benar karena fakta $\mathrm{E}$.

2) Nilai $C F($ rule) didapat dari interprtasi "term" dari pakar, yang diubah menjadi nilai CF tertentu sesuai tabel berikut: 


\section{TABEL I. FAKTOR KEYAKINAN PAKAR}

\begin{tabular}{|c|c|}
\hline Certainty Term & CFAkhir \\
\hline Definitely not (pasti tidak) & -1.0 \\
\hline $\begin{array}{c}\text { Almost certainly not (hampir } \\
\text { pasti tidak) }\end{array}$ & -0.8 \\
\hline $\begin{array}{c}\text { Probably not (kemungkinan } \\
\text { besar tidak) }\end{array}$ & -0.6 \\
\hline Maybe not (mungkin tidak) & -0.4 \\
\hline Unknown (tidak tahu) & $-0.2---0.2$ \\
\hline Maybe (mungkin) & 0.4 \\
\hline Probably (kemungkinan besar) & 0.6 \\
\hline Almost certainly (hampir pasti) & 0.8 \\
\hline
\end{tabular}

\section{METODE PENELITIAN}

\section{A. Kerangka Kerja Penelitian}

Adapun kerangka kerja dalam penelitian ini sebagai berikut:
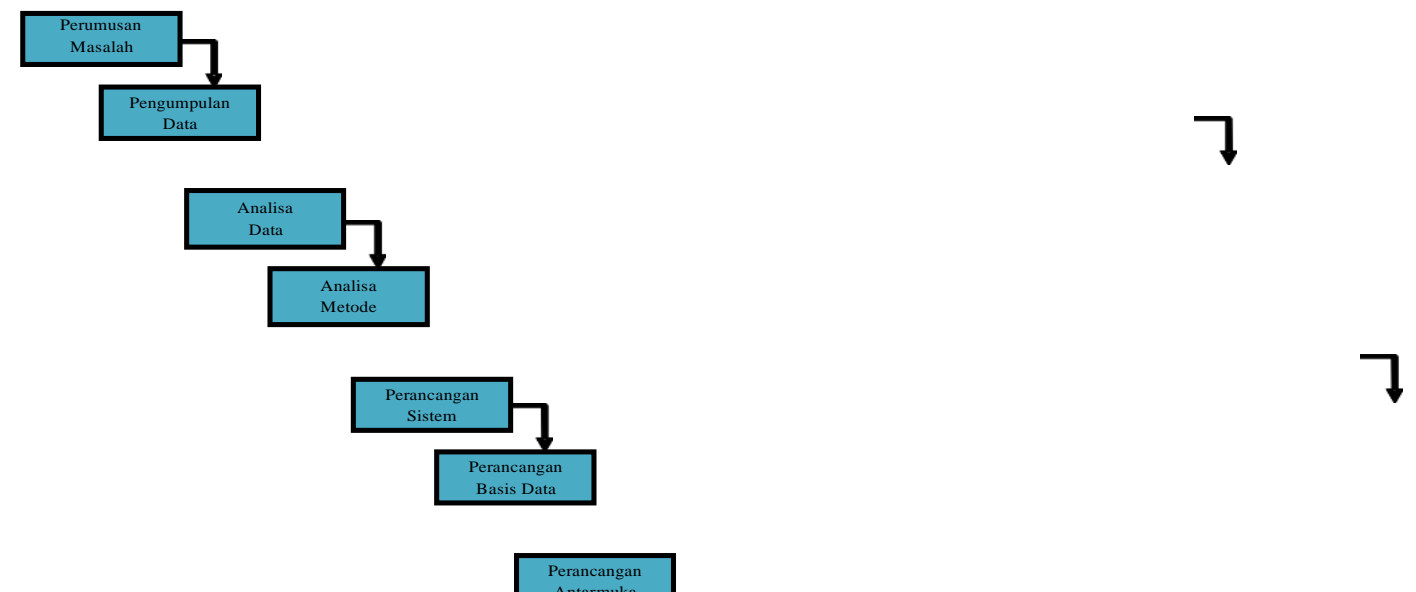

Gambar. 1. Kerangka Kerja Penelitian

B. Uraian Kerangka Kerja

V. Pengumpulan Data. Dalam penelitian ini maka metode pengumpulan data yang digunakan adalah Wawancara (Interview) dan Studi Literatur

VI. Analisa. Analisa merupakan tahap awal yang dilakukan untuk pengembangan Sistem Pakar Mendiagnosa Penyakit Saraf Pusat Manusia Dengan Metode Certainty Factor, seperti Analisa Data dan Analisa Metode

VII. Perancangan. Adapun perancangan-perancangan yang dibuat meliputi Perancangan Sistem yang Diusulkan, Perancangan Database, Perancangan Masukan, Perancangan keluaran, dan Perancangan Antarmuka SistemEquations

\section{Tempat Penelitian}

Awal berdirinya Rumah Sakit Umum Siti Hajar Medan Berawal dari pendirian sebuah praktek dokter yang pelaksanaannya ditangani oleh Alm.dr, HM. Mochtar Tarigan DSP, yaitu sekitar tahun 1973 degan system pelayanan berobatjalan yang masih sederhana

e. Saraf PusatSistem syaraf pusat terdiri dari otak dan medula spinalis. Otak memiliki tiga fungsi yaitu input sensorik dari medulla spinalis maupun dari syarafnya sendiri, memproses berbagai input sensorik yaitu fungsi kognisi yang meliputi integrasi, dan asosiasi data yang tersimpan serta komponen emosi, menginisialisasi 
dan mengkoordinasi output motorik. [10]

A. Analisa

\section{ANALISA DAN PERANCANGAN}

1) Analisa Data. Analisa data terdiri dari 3 pembahasan yaitu tempat penelitian, analisa kebutuhan sistem dan analisa sistem yang dibangun.

2) Analisa Metode Certainty Factor. Untuk proses penentuan jenis penyakit apa yang dialami oleh sipenderita diperlukan data dan rule untuk diolah sebagai basis aturan penentu jenis penyakit apa yang dialami oleh sipenderita.

\section{TABEL II. DATA GEJALA PENYAKIT SARAF PUSAT MANUSIA}

\begin{tabular}{|c|c|c|}
\hline No & $\begin{array}{l}\text { Kode } \\
\text { Gejala }\end{array}$ & Gejala \\
\hline 1 & G01 & Kejang \\
\hline 2 & G02 & Melamun \\
\hline 3 & G03 & Jatuh tanpa sebab \\
\hline 4 & G04 & Mulut berkomat kamit \\
\hline 5 & G05 & $\begin{array}{l}\text { Kelopak mata berkedip secara tidak } \\
\text { wajar }\end{array}$ \\
\hline 6 & G06 & Nyeri kepala \\
\hline 7 & G07 & Muntah \\
\hline 8 & G08 & Penglihatan kabur \\
\hline 9 & G09 & Nyeri punggung \\
\hline 10 & G10 & Halusinasi \\
\hline 11 & G11 & Demam \\
\hline 12 & G12 & Mual \\
\hline 13 & G13 & Gangguan pernapasan \\
\hline 14 & G14 & Diare \\
\hline 15 & G15 & Nafsu makan berkurang \\
\hline 16 & G16 & Berat badan turun \\
\hline 17 & G17 & Konstipasi \\
\hline 18 & G18 & Nyeri otot \\
\hline 19 & G19 & Mudah lelah \\
\hline 20 & G20 & Tidur terganggu \\
\hline 21 & G21 & Kelopak mata tidak bisa ditutup \\
\hline 22 & G22 & Wajah melorot \\
\hline 23 & $\mathrm{G} 23$ & Wajah susah berekspresi \\
\hline 24 & G24 & Peka terhadap suara \\
\hline 25 & $\mathrm{G} 25$ & Penurunan kemampuan indera pengecap \\
\hline 26 & G26 & Tremor/gemetar \\
\hline 27 & $\mathrm{G} 27$ & $\begin{array}{l}\text { Hilangnya gerak asosiasi lengan bila } \\
\text { berjalan }\end{array}$ \\
\hline 28 & G28 & Gerakan melamban \\
\hline 29 & G29 & Kulit muka seperti berminyak \\
\hline 30 & G30 & Berkurangnya gerak menelan air liur \\
\hline 31 & G31 & Volume suara berkurang \\
\hline 32 & G32 & Penglihatan ganda \\
\hline 33 & G33 & $\begin{array}{l}\text { Gangguan berjalan/perubahan cara } \\
\text { berjalan }\end{array}$ \\
\hline 34 & G34 & Gangguan daya ingat/pelupa \\
\hline 35 & G35 & Pembesaran kepala \\
\hline 36 & G36 & Tidak enak badan \\
\hline 37 & G37 & Nyeri tenggorokan \\
\hline 38 & G38 & Tenggorokan tampak merah \\
\hline 39 & G39 & Kaku duduk \\
\hline
\end{tabular}

This is an Creative Commons License This work is licensed under a Creative Commons AttributionNonCommercial 4.0 International License. 


\begin{tabular}{|c|c|l|}
\hline 40 & G40 & Nyeri leher \\
\hline 41 & G41 & Nyeri tungkai otot betis \\
\hline 42 & G42 & Otot kaku \\
\hline 43 & G43 & Peka terhadap sentuhan \\
\hline 44 & G44 & Gangguan menelan \\
\hline 49 & G49 & Gelisah \\
\hline 50 & G50 & Rasa berat di tengkuk \\
\hline 51 & G51 & Kehilangan keseimbangan \\
\hline 52 & G52 & $\begin{array}{l}\text { Lengan dan kaki kanan tidak } \\
\text { bertenaga }\end{array}$ \\
\hline 53 & G53 & Kesemutan \\
\hline 54 & G54 & Melemahnya otot lengan atas \\
\hline 55 & G55 & Melemahnya otot bahu \\
\hline 56 & G56 & Terbatasnya anggota gerak \\
\hline 57 & G57 & Peka terhadap cahaya \\
\hline 58 & G58 & Peka terhadap bau-bauan \\
\hline 59 & G59 & Lekas marah \\
\hline 60 & G60 & Murung \\
\hline 61 & G61 & Menguap berlebihan \\
\hline 62 & G62 & Pusing \\
\hline 63 & G63 & $\begin{array}{l}\text { Nyeri disekitar } \\
\text { rahang/dibelakangtelinga }\end{array}$ \\
\hline 64 & G64 & Keringat berlebihan \\
\hline
\end{tabular}

TABLE III. DATA PENYAKIT SARAF PUSAT MANUSIA

\begin{tabular}{|c|c|l|}
\hline No & $\begin{array}{c}\text { Kode } \\
\text { Penyak } \\
\text { it }\end{array}$ & \multicolumn{1}{|c|}{ Nama Penyakit } \\
\hline 1 & P01 & Epilepsi \\
\hline 2 & P02 & Meningitis \\
\hline 3 & P03 & Bell's Palsy \\
\hline 4 & P04 & Parkinson \\
\hline 5 & P05 & Hidrosefalus \\
\hline 6 & P06 & Poliomielitis \\
\hline 7 & P07 & Alzheimer \\
\hline 8 & P08 & Stroke \\
\hline 9 & P09 & ALS \\
\hline 10 & P10 & Migrain \\
\hline
\end{tabular}

TABLE IV.DATA PENCEGAHAN PENYAKIT SARAF PUSATMANUSIA

\begin{tabular}{|c|c|c|c|}
\hline No & $\begin{array}{c}\text { Kod } \\
\text { Peny } \\
\text { akni }\end{array}$ & $\begin{array}{c}\text { Peamya } \\
\text { kit }^{\text {nama }}\end{array}$ & \multicolumn{1}{c|}{ Pencegahan } \\
\hline 1 & P01 & Epilepsi & $\begin{array}{l}\text { Hingga penelitian sedang dilakukan, belum ada metodemaupun obat untuk } \\
\text { menyembuhkan epilepsi. untuk mencegah terjadinya kejang pada penderita maka dapat } \\
\text { diberikanobat anti epilepsi atau OAE sehingga penderita tetap dapat } \\
\text { melakukan kegiatan dan aktivitas }\end{array}$ \\
\hline
\end{tabular}




\begin{tabular}{|c|c|c|c|}
\hline & & & $\begin{array}{l}\text { sehari-hari dengan normal. Untuk pencegahan epilepsi dapat dilakukan dengan pola hidup yang } \\
\text { sehat dengan olahraga secara teratur dan tidak minum } \\
\text { minuman yang beralkohol }\end{array}$ \\
\hline 2 & P02 & Meningitis & $\begin{array}{l}\text { Untuk pengobatan penyakit meningitis berbeda-beda bergantung kepada apa penyebabnya. } \\
\text { pengobatan dapat dilakukan, dengan pemberian resep obat antimikroba oleh dokter, menjalankan } \\
\text { terapi apabila peneybabnya adalah kanker atau lupus. Penyakit Meningitis bisa dicegah dengan } \\
\text { menjalani gaya hidup yang sehat dan menghindari kondisi atau kegiatan yang dapat memicu } \\
\text { penyebaran infeksi. Untuk meningkatkan kekebalan tubuh terhadap kuman penyebab meningitis, } \\
\text { bisa dengan vaksinasi } \\
\text { sesuai dengan anjuran dokter. }\end{array}$ \\
\hline 3 & P03 & $\begin{array}{l}\text { Bell's } \\
\text { Palsy }\end{array}$ & $\begin{array}{l}\text { Untuk penderita penyakit Bell's Palsy, lakukan terapi Bell's palsy, tujuannya agak mempercepat } \\
\text { penyembuhan dan mencegah timbulnya komplikasi. Untuk terapi tersebut harap melakukan } \\
\text { konsultasi lebih lanjut dengan } \\
\text { dokter ahli dibidangnya }\end{array}$ \\
\hline 4 & P04 & Parkinson & 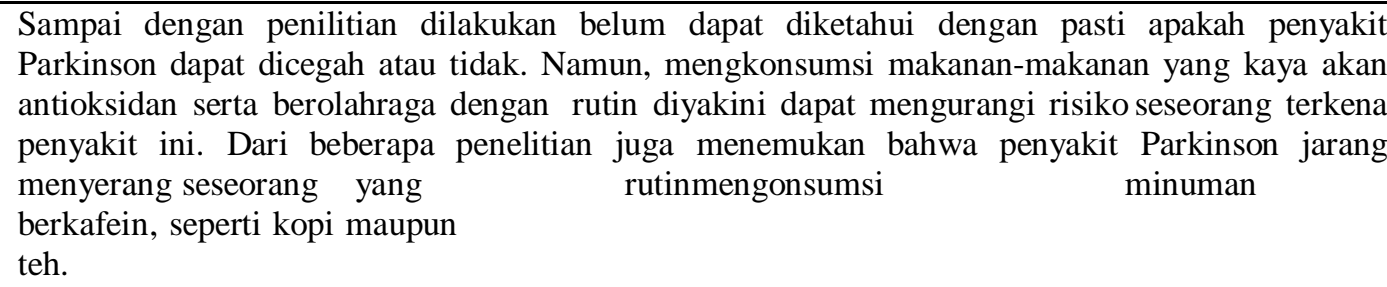 \\
\hline \multirow[t]{2}{*}{5} & P05 & $\begin{array}{l}\text { Hidrosefal } \\
\text { us }\end{array}$ & $\begin{array}{l}\text { Pengobatan utama } \\
\text { penyakit hidrosefalus }\end{array}$ \\
\hline & & & $\begin{array}{l}\text { dengan melalui operasi. Tujuan dilakukannya operasi adalah untuk membuang kelebihan cairan } \\
\text { serebrospinal yang ada di dalam otak. Salah satu jenis operasi yang biasanya diterapkan pada } \\
\text { kasus hidrosefalus adalah operasi pemasangan shunt. (Shunt adalah alat khusus berbentuk selang } \\
\text { yang dipasangkan oleh ahli bedah ke dalam kepala guna mengalirkan cairan otak yang berlebih ke } \\
\text { bagian tubuh lain dan diserap } \\
\text { oleh pembuluh darah) }\end{array}$ \\
\hline 6 & P06 & $\begin{array}{l}\text { Poliomielit } \\
\text { is }\end{array}$ & $\begin{array}{l}\text { Penyakit ini dapat dicegah dengan vaksinasi. Tujuannya adalah untuk memberikan kekebalan } \\
\text { terhadap penyakit polio seumur hidup, terutama pada anak-anak. Orang dewasa yang belum } \\
\text { pernah divaksinasi atau status vaksinasinya tidak jelas harus menjalani serangkaian } \\
\text { vaksin polio. }\end{array}$ \\
\hline 7 & P07 & Alzheimer & $\begin{array}{l}\text { Penyakit Alzheimer bisa dicegah dengan beberapa cara, misalnya dengan berhenti merokok, } \\
\text { menjaga berat badan agar tetap ideal, mengonsumsi makanan- } \\
\text { makanan dengan gizi seimbang, dan rutin berolahraga }\end{array}$ \\
\hline 8 & P08 & Stroke & 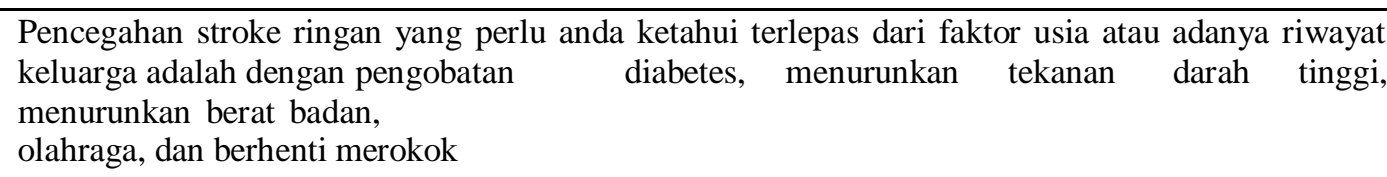 \\
\hline
\end{tabular}




\begin{tabular}{|l|l|l|l|}
\hline 9 & P09 & ALS & $\begin{array}{l}\text { Gaya hidup dan pengobatan rumahan berikut mungkin dapat membantu mengatasi } \\
\text { Amyotrophic Lateral Sclerosis seperti memilih pengobatan yang diperlukan untuk mengatasi } \\
\text { masalah tertentu seperti bernapas dan makan. Kemudian pelajari sebanyak mungkin tentang } \\
\text { penyakit ALS dan cara } \\
\text { mengurangi gejalanya, atau }\end{array}$ \\
\hline
\end{tabular}

\begin{tabular}{|l|l|l|l}
\hline & & bergabunglah dalam gruppendukung untuk kondisi ALS. \\
\hline \multirow{2}{*}{ P10 } & Migrain & $\begin{array}{l}\text { Penyakit migrain tidak dapat disembuhkan, namun dengan pengobatan dapat membantu } \\
\text { meredakan gejalanya bagipenderitanya. Penanganan migrain dapat dilakukan } \\
\text { dengan berdasarkan jenis migrain yang dialami, tingkat keparahan migrain, umur, dan } \\
\text { kondisi kesehatan penderita. Tujuan dari penanganan tersebut adalah hanya untuk } \\
\text { membantu menghentikan gejala serta mencegah terjadinya serangan migrain berikutnya. } \\
\text { Penanganan yang dapat dilakukan adalah memijat kepala atau pelipis, beristirahat atau } \\
\text { tidur di kamaryang sepi dan gelap, melakukan relaksasi otot, dan kompres dingin di atas } \\
\text { dagu atau di } \\
\text { belakang leher. }\end{array}$ \\
\hline
\end{tabular}

TABLE V. BOBOT NILAI CERTAINTY FACTOR

\begin{tabular}{|c|c|c|c|c|c|c|c|c|c|c|}
\hline \multirow{2}{*}{$\begin{array}{l}\text { Kode } \\
\text { Gejala }\end{array}$} & \multicolumn{10}{|c|}{ Kode Jenis Penyakit } \\
\hline & P01 & $\begin{array}{l}\mathbf{P 0 2} \\
\mathrm{P}\end{array}$ & $\mathbf{P 0 3}$ & P04 & P05 & P06 & P07 & P08 & P09 & P10 \\
\hline 1 & 1 & 0.6 & & & 0.2 & 0.2 & & & & \\
\hline 2 & 0.4 & & & & & & & & & \\
\hline 3 & 1 & & & & & & & & & \\
\hline 4 & 1 & & & & & & & & & \\
\hline 5 & 0.8 & & & 0.2 & & & & & & \\
\hline 6 & 0.6 & 0.8 & 0.8 & & 0.8 & 0.6 & & 1 & & 0.8 \\
\hline 7 & 0.6 & 0.8 & & & 0.6 & 0.4 & & & & 0.4 \\
\hline 8 & 0.6 & & & & & & & 0.8 & & \\
\hline 9 & 0.6 & & & & & 0.8 & & & & \\
\hline 10 & 0.8 & & & 0.4 & & & 0.8 & & & 0.2 \\
\hline 11 & & 1 & & & & 0.8 & & & & \\
\hline 12 & & 0.8 & & & & & & & & 0.4 \\
\hline 13 & & 0.6 & & & & & & & & \\
\hline 14 & & 0.6 & & & & 0.2 & & & & \\
\hline 15 & & 0.8 & & & & & & & & 0.2 \\
\hline 16 & & 0.6 & & & & & & & & \\
\hline 17 & & 1 & & & & & & & & \\
\hline 18 & & & & & & 0.8 & & & & \\
\hline 19 & & 0.8 & & & & & & & 0.8 & \\
\hline 20 & & 0.8 & & & & & & & & \\
\hline 21 & & & 0.8 & & & & & & & \\
\hline 22 & & & 1 & & & & & & & \\
\hline 23 & & & 1 & 0.4 & & & & & & \\
\hline 24 & & & 1 & & & & & & & 0.8 \\
\hline 25 & & & 1 & & & & & & & \\
\hline
\end{tabular}

\begin{tabular}{|c|l|l|c|c|c|c|c|c|c|c|}
\hline Kode & \multicolumn{7}{|c|}{ Kode Jenis Penyakit } \\
\hline Gejala & & & & 1 & & & \\
\hline 27 & & & & 0.2 & & & & & & \\
\hline 28 & & & & 1 & & & & & & \\
\hline 29 & & & & 0.2 & & & & & & \\
\hline 30 & & & & 0.2 & & & & & 0.6 & \\
\hline 41 & & & & 0.6 & & & & & & \\
\hline 42 & & & & & 0.4 & & & & & \\
\hline 43 & & & & & 0.8 & & 0.6 & & 0.6 & \\
\hline 44 & & & & & 1 & & 1 & & & \\
\hline 45 & & & & & 0.8 & & & & & \\
\hline 46 & & & & & & 0.2 & & & & \\
\hline 47 & & & & & & 0.8 & & & & \\
\hline 48 & & & & & & 0.2 & & & & \\
\hline 49 & & & & & & 0.4 & & & & \\
\hline 50 & & & & & & 0.8 & & & & \\
\hline 51 & & & & & & 0.8 & & & & \\
\hline 52 & & & & & & 1 & & & & \\
\hline 53 & & & & & & 0.4 & & & & \\
\hline 54 & & & & & & 0.6 & & & 0.8 & \\
\hline 55 & & & & & & & 0.6 & 0.4 & 0.8 & \\
\hline 56 & & & & & & & & & 0.4 & \\
\hline 57 & & & & & & & 0.2 & & & \\
\hline 58 & & & & & & & 0.4 & & & \\
\hline 59 & & & & & & & 0.2 & & & \\
\hline 60 & & & & & & & & 0.6 & & \\
\hline 61 & & & & & & & & 0.8 & & 0.4 \\
\hline 62 & & & & & & & & 0.6 & & \\
\hline 63 & & & & & & & & 0.2 & & \\
\hline 64 & & & & & & & & & 0.8 & \\
\hline
\end{tabular}

This is an Creative Commons License This work is licensed under a Creative Commons Attribution- 
TABLE VI.KAIDAH (RULE)

\begin{tabular}{|c|c|l|l|}
\hline $\begin{array}{c}\text { N } \\
\text { o }\end{array}$ & $\begin{array}{c}\text { Ped } \\
\text { ya } \\
\text { kit }\end{array}$ & $\begin{array}{c}\text { Nama } \\
\text { Penya } \\
\text { kit }\end{array}$ & \multicolumn{1}{c|}{ Kaidah (Rule) } \\
\hline 1 & P01 & Epilepsi & $\begin{array}{l}\text { IF kejang (G01) AND melamun (G02) AND jatuh tanpa sebab (G03) AND mulut berkomat-kamit (G04) AND } \\
\text { kelopak mata berkedip secaratidak wajar (G05) AND nyeri kepala (G06) AND muntah (G07) AND } \\
\text { penglihatan kabur (G08) AND nyeri punggung (G09) AND halusinasi (G10) THEN Epilepsi. }\end{array}$ \\
\hline 2 & P02 & Meningitis & $\begin{array}{l}\text { IF demam (G11) AND mual (G12) AND muntah (G07) AND gangguan pernapasan (G13) AND kejang (G01) } \\
\text { AND nyeri kepala(G06) AND nyeri otot AND nyeri punggung (G19)AND tidur terganggu (G20) THEN } \\
\text { Meningitis. }\end{array}$ \\
\hline 3 & P03 & Bell's Palsy & $\begin{array}{l}\text { IF kelopak mata sulit ditutup (G21) AND nyeri kepala (G06) AND wajah turun/melorot (G22) AND mukasusah } \\
\text { berekspresi (G23) AND peka } \\
\text { terhadap suara (G24) AND nyeri }\end{array}$ \\
\hline
\end{tabular}

\begin{tabular}{|l|l|l|l|}
\hline & & disekitar rahang/dibelakang telinga pada salah satu wajah yang terpengaruh (G63) AND penurunan kemampuan \\
\hline
\end{tabular}

\begin{tabular}{|c|c|l|l|}
\hline & & $\begin{array}{l}\text { disekitar rahang/dibelakang telinga pada salah satu wajah yang terpengaruh (G63) AND penurunan kemampuan } \\
\text { indera pengecap pada sisi } \\
\text { yang lumpuh (G25) THEN Bell's Palsy. }\end{array}$ \\
\hline 4 & P04 & Parkinson & $\begin{array}{l}\text { IF tremor/gemetar (G26) AND hilangnya gerak asosiasilengan bila berjalan (G27) AND gerakan melamban } \\
\text { (G28)AND wajah susah berekspresi (G23) AND kelopakmataberkedip secara tidak wajar(G05) AND kulit muka } \\
\text { sepertiberminyak (G29) AND berkurangnya gerak menelan airliur(G30) AND keringat berlebihan (G64) AND } \\
\text { volume suaraberkurang(G31) AND halusinasi (G10) THEN } \\
\text { Parkinson. }\end{array}$ \\
\hline 5 & P05 & Hidrosefalus & $\begin{array}{l}\text { IF nyeri kepala (G06) AND muntah (G07) AND penglihatan ganda (G32) AND } \\
\text { berjalan/gangguan berjalan (G33) AND gangguan daya ingat (G34)AND pembesaran kepala (G35) AND } \\
\text { kejang (G01) THEN Hidrosefalus. }\end{array}$ \\
\hline 6 & P06 & Poliomielitis & $\begin{array}{l}\text { IF demam (G11) AND nyeri kepala (G06)AND tidak enak badan (G36) AND nyeri tenggorokan (G37) AND } \\
\text { tenggorokan tampak merah (G38) AND muntah (G07) AND kaku duduk (G39) AND diare (G14) AND kejang } \\
\text { (G01) AND nyeri otot (G18) ANDnyeri leher (G40) AND nyeri punggung (G09) AND nyeri tungkai otot betis } \\
\text { (G41) AND otot kaku (G42)AND peka terhadap sentuhan (G43) AND gangguan menelan (G44) } \\
\text { THEN Poliomielitis. }\end{array}$ \\
\hline 7 & P07 & Alzheimer & $\begin{array}{l}\text { IF gangguan memori/pelupa (G34) AND bicara menjadi tidak jelas (G45) AND pengulangan kata (G47) AND } \\
\text { kemampuan aritmatik terganggu (G48) AND gelisah (G49) AND lekasmarah (G59) AND murung (G60) AND } \\
\text { halusinasi (G10) ANDgangguan berjalan (G33) THEN } \\
\text { Alzheimer. }\end{array}$ \\
\hline 9 & P08 & Stroke & $\begin{array}{l}\text { IF nyeri kepala (G06) AND bicara menjadi tidak jelas/gangguan bicara (G45) AND rasa berat di tengkuk } \\
\text { (G50)AND penglihatan kabur (G08) AND kehilangan keseimbangan(G51) AND lengan dan kaki kanan tidak } \\
\text { bertenaga (G52) AND } \\
\text { kesemutan (G53) THEN Stroke. }\end{array}$ \\
\hline P09 & ALS & $\begin{array}{l}\text { IF melemahnya otot lengan atas (G54) AND melemahnya otot bahu (G55) AND terbatasnya anggota gerak } \\
\text { (G33) ANDkedutan ringan dibawah permukaan kulit (G46) AND gangguan bicara/bicara menjadi tidak jelas } \\
\text { (G45) AND sulit menelan (G44) } \\
\text { AND mudah lelah (G19) AND }\end{array}$ \\
\hline
\end{tabular}

\begin{tabular}{|l|l|l|l|}
\hline & & & $\begin{array}{l}\text { berkurangnya gerak menelan air liur } \\
\text { (G30) THEN ALS. }\end{array}$ \\
\hline \multirow{3}{*}{10} & P10 & Migrain & $\begin{array}{l}\text { IF nyeri kepala (G06) AND mual (G12) AND muntah (G07) AND peka terhadap } \\
\text { cahaya (G57) AND peka terhadap suara (G24) AND peka terhadap bau-bauan } \\
\text { (G58) AND lekas marah (G59) AND murung (G60) AND nafsu makan berkurang } \\
\text { (G15) AND hilangnya keseimbangan (G51) AND menguap berlebih (G61) AND } \\
\text { pusing (G62) AND halusinasi (G10) } \\
\text { THEN Migrain. }\end{array}$ \\
\hline
\end{tabular}

This is an Creative Commons License This work is licensed under a Creative Commons Attribution- 


\section{Perancangan Sistem}

Untuk Perancagan sistem maka menggunakan teknik pemrograman berorientasi objek, yaitu Unified Modeling Language (UML)[11].

Perancangan sistem yang diusulkan sebagai berkut:

- Use Case Diagram

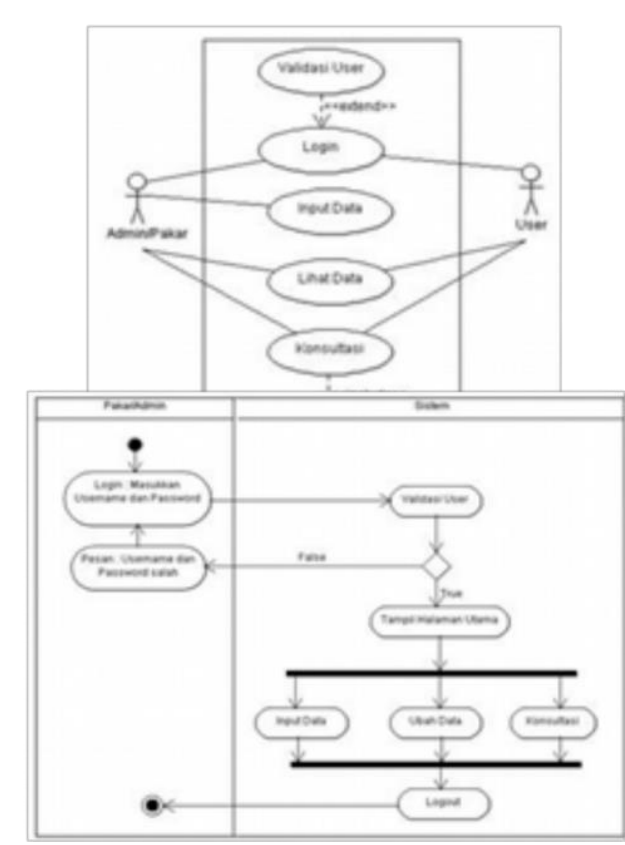

Gambar. 2. Use Case Diagram Sistem

- Activity diagram

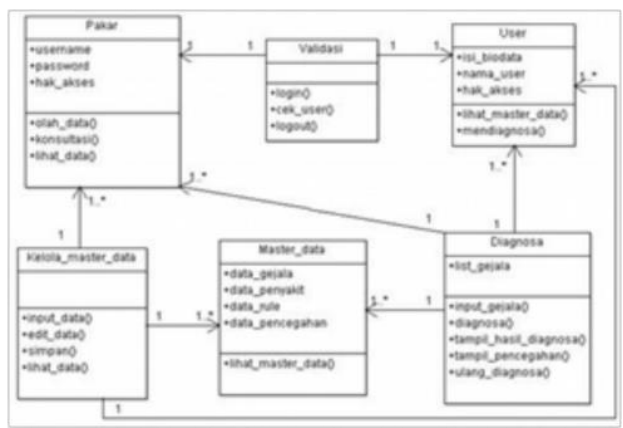

Gambar. 3. Activity Diagram Sistem

- Class diagram

Gambar. 4. Class diagram Sistem

- Squence Diagram 


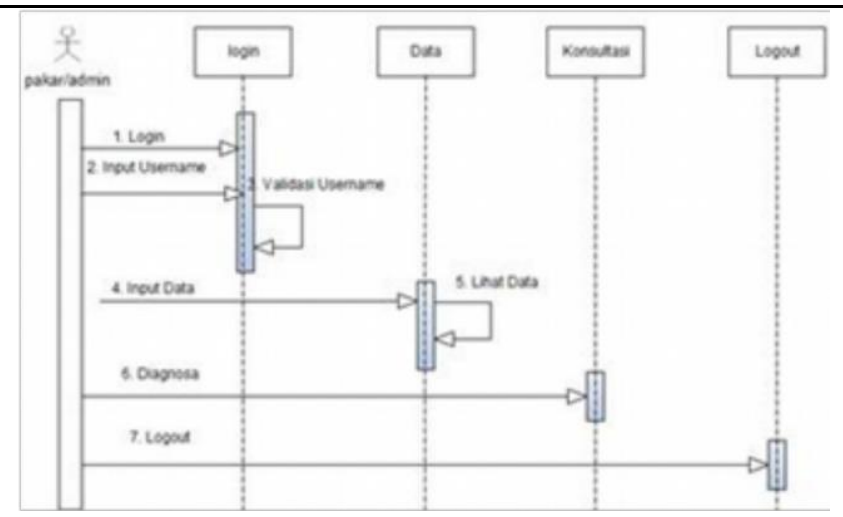

Gambar. 5. Squence Diagram Pakar/Admin

\section{IMPLEMENTASI SISTEM}

\section{A. Kebutuhan Perangkat Lunak}

Perangkat lunak yang digunakan dalam membangun Sistem Pakar ini adalah Sistem Operasi Windows 7 Ultimate 64-Bit, Microsoft Visual Studio 2010[12], SAP Crystal Report, Microsoft Access 2010.

\section{B. Implementasi}

1) Halaman Login. Pada halaman login ini, setiap pengguna akan melihat menu dan form isian untuk melakukan login, baik sebagai pakar/admin maupun pengguna umum.

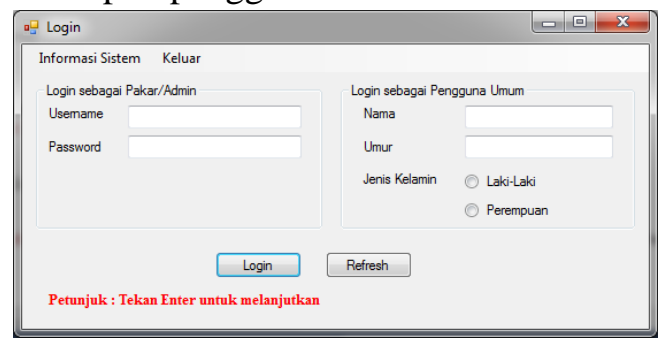

Gambar. 6. Halaman Login

2) Halaman Utama. Halaman utama ini merupakan halaman yang akan menampilkan sub-sub menu setelah login, seperti menu tab file, menu tab editor, menu tab diagnosa dan menu tab keluar.

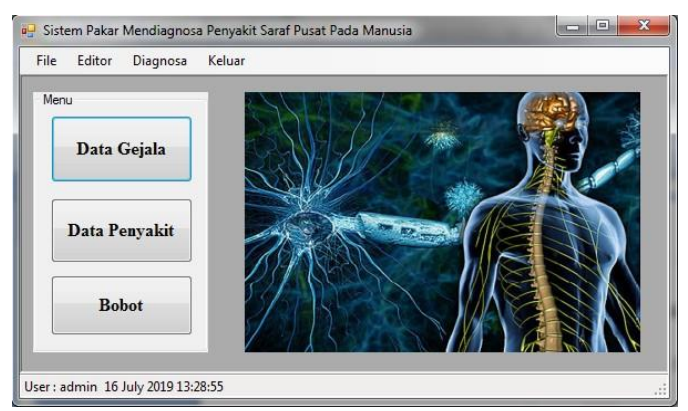

Gambar. 7. Halaman Utama

3) Halaman Pengolahan Data Gejala. Halaman pengolahan data gejala merupakan halaman dalam mengolah data gejala seperti menambah maupun mengubah data gejala. 


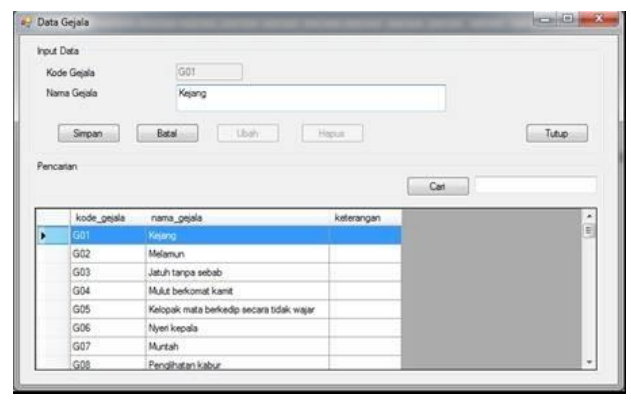

Gambar. 8. Halaman Pengolahan Data Gejala

4) Halaman Pengolahan Data Penyakit dan Pencegahan. Halaman pengolahan data penyakit dan pencegahan merupakan halaman dalam mengolah data penyakit dan pencegahan seperti menambah maupun mengubah data penyakit dan pencegahan.

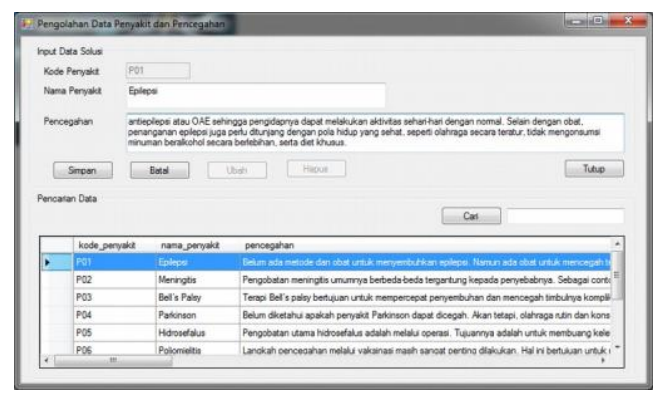

Gambar. 9. Halaman Pengolahan Data Penyakit danPencegahan

5) Halaman Pengolahan Data Relasi/Bobot. Halaman pengolahan data relasi/bobot merupakan halaman dalam mengolah data relasi/bobot seperti menambah maupun mengubah data relasi/bobot

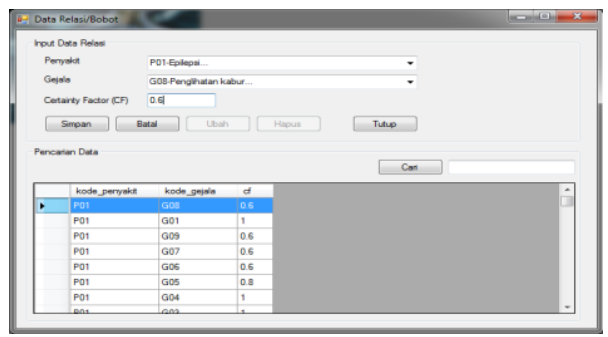

Gambar. 10. Halaman Pengolahan Data Relasi/Bobo

6) Halaman Diagnosa. Halaman diagnosa merupakan halaman untuk konsultasi oleh sipengguna. Pada halaman ini, sipengguna juga akan langsung bisa melihat hasil konsultasi. Untuk gambar halaman diagnosa dapat dilihat pada

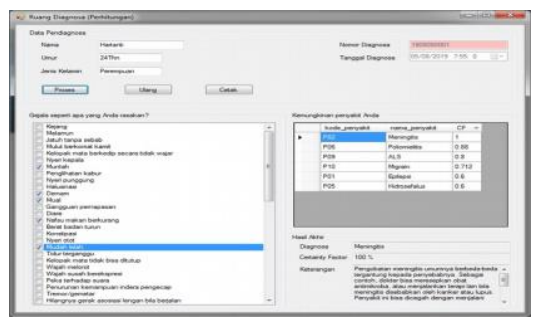

This is an Creative Commons License This work is licensed under a Creative Commons Attribution- 
gambar berikut ini:

Gambar. 11. Halaman Diagnosa

7) Halaman Laporan Hasil Diagnosa. Halaman laporan hasil diagnosa adalah halaman yang berisi data hasil diagnosa dalam bentuk laporan yang bisa di cetak.

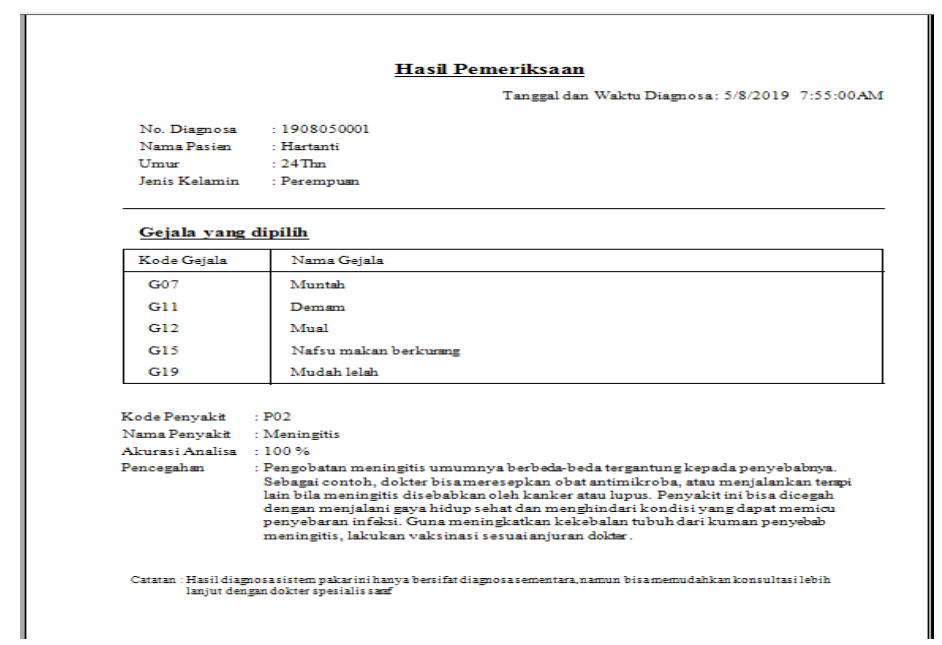

Gambar. 12. Halaman Laporan Hasil Diagnosa

\section{KESIMPULAN DAN SARAN}

\section{A. Kesimpulan}

Setelah dilakukan pengujian-pengujian yang diperlukan terhadap sistem pakar yang telah dibangun yaitu Sistem Pakar Mendiagnosa Penyakit Saraf Pusat Manusia Dengan Metode Certainty Factor, maka dapat diperoleh kesimpulan sebagai berikut :

- Sistem yang telah dibangun mampu memberikan gambaran kemungkinan penyakit saraf apa yang diidap si pengguna berdasarkan gejala yang dialaminya

- Sistem yang telah dibangun mampu memberikan gambaran berupa informasi kemungkinan penyakit saraf apa yang diidap dan pencegahan yang dapat dilakukan, yang dalam hal ini tentunya sipemakai sistem tidak lagi harus mengeluarkan biaya mahal jika hanya sekedar ingin konsultasi.

- Selain mampu memberikan gambaran kemungkinan penyakit saraf apa yang diidap dan pencegahan yang dapat dilakukan kepada pengguna sistem, sistem inijuga dapat membantu pihak Rumah Sakit untuk membantu pasien yang mengantri untuk konsultasi sehingga jika terjadi kekurangan tenaga medis dalam konsultasi dapat terbantu.

\section{B. Saran}

Adapun saran untuk melengkapi kesimpulan yang diambil untuk kesempurnaan hasil penelitian/pemecahan masalah dimasa yang akan datang adalah sebagai berikut:

- Sistem pakar yang sudah di bangun masih jauh tentunya dari sempurna untuk itu sangat perlu dilakukan perbaikan-perbaikan maupun pembaruan demi kesempurnaan sistem dan juga kemudahan dalam penggunaanya bagi sipengguna, seperti sistem masih bersifat offline dan berbasis dekstop, mungkin dimasa mendatang dapat dibuatkan bersifat online dan berbasismobile sehingga tempat dan penggunaannya tidak lagi terbatas.

- Sistem pakar ini memiliki fitur-fitur sangat sederhana, sehingga kedepannya diharapkan peningkatan fiturfiturnya seperti fitur menambah user pakar/admin, atau fitur untuk menampilkan profile dokter spesialis saraf apabila dibutuhkan konsultasi lebih jauh terhadap penyakit yang diderita.

- Sistem pakar ini memiliki interface yang sangat sederhana, sehingga kedepannya diharapkan peningkatan dengan menambahkan gambar-gambar yang bisa menjelaskan lebih detail mengenai saraf pusat pada manusia sehingga interface sistem pakar ini lebih menarik. 


\section{XII.DAFTAR PUSTAKA}

Daniel Alexander Octavianus Turang. (Februari, 2018). Aplikasi Sistem Pakar Berbasis Web Untuk Mendiagnosa Penyakit Syaraf Pusat Dengan Metode Forward Chaining. KLIK. vol 5, no. 1, hal. 87-97.

Hendra Marcos dan Galuh Kusumastuti. (Agustus, 2016). Sistem Pakar Diagnosis Penyakit Saraf Pusat dengan Metode Forward Chaining. CITISEE 2016. hal 9-15

Muhammad Muslihudin dan Oktafianto, "Konsep Dasar Sistem Informasi," dalam Analisis dan Perancangan Sistem Informasi, edisi pertama, Yogjakarta, Indonesia, 2016, bab I, bagi Definisi Sistem, hal. 3.

Poni Wijayanti dan Abdul Fadlil. (Februari, 2014). Sistem Pakar Mendiagnosa Jenis Penyakit Stroke Menggunakan Metode Certainty Factor. Jurnal Sarjana Teknik Informatika. vol 2, n0. 1, hal. 1221

T. Sutojo, Edy Mulyanto, \& Dr. Vinvent Suhartono, “judulbab,” dalam Kecerdasan Buatan, Yogjakarta, Indonesia, 2011, Bab, Bag, Hal.

Clara Hetty Primasari. (April, 2018). Aplikasi Web SistemPakar untuk Diagnosis Penyakit Gizi. JUTEI. Vol 1, no. 1, hal. 1-10.

Rika Rosnelly, "Konsep Sistem Pakar," dalam Sistem Pakar: Konsep dan Teori, edisi pertama, Yogyakarta, Indonesia, 2012, bab I, hal 2.

Fitri Wulandari dan Ihsan Yuliandri. (Juni, 2014). Diagnosa Gangguan Gizi Menggunakan Metode Certainty Factor. Jurnal Sains, Teknologi dan Industri. vol 11, no. 2, hal. 305-313.

Herry Hidayat dan Danny Kriestanto. (Maret, 2015). Analisis Metode Sistem Pakar Untuk Menentukan Jenis Penyakit Dalam Dengan Metode Certainty Factor. Jurnal Teknologi Informasi. vol X, n0. 28, hal 1-15

Paryati. (November, 2015). Aplikasi Farmakoterapi Sistem Pakar Berbasis Web Untuk Mendiagnosa Penyakit Syaraf Pusat. semnasIF 2015. hal. 233- 244.

Rosa A.S. dan M. Shalahuddin, "Judul bab dalam buku," dalam Rekayasa Perangkat Lunak, edisi X, Bandung, Indonesia, 2018, bab x, bagian x, hal. $\mathrm{x}$.

Rolly Yesputra, "Menyiapkan ruang Kerja," dalam Belajar Visual Basic. Net Dengan Visual Studio 2010, edisi pertama, Kisaran, Indonesia, 2017, bab I, bagian Apa I

tu VB 2010?, hal. 1. 